\title{
Influence of the Print Run on Silver Halide Printing Plates
}

\author{
Authors: Tomislav Cigula ${ }^{1}$, Sanja Mahović Poljaček ${ }^{1}$, Miroslav Gojo ${ }^{1}$ \\ ${ }^{1}$ University of Zagreb, Faculty of Graphic Arts, Zagreb, Croatia
}

\begin{abstract}
The most common printing technique today is lithography. The difference between printing and nonprinting areas on a printing plate is accomplished by opposite physical and chemical properties of those areas (MacPhee, 1998). The printing areas are made of photoactive layer that attracts oil and chemical substances with oil solvent - printing inks. The nonprinting areas are made of aluminium-oxide which attracts water based substances - the fountain solution.

There are many of various types of photoactive layer which are used for production of offset printing plates, among others is silver halide layer. The usage of the silver halide technology in the graphic reproduction is not a novelty. The filmmaking phase is based on the usage of the silver halide as the photographically active ingredient, for instance, $\mathrm{AgBr}$ (silver bromide). The new, digital plate making technology (Computer to Plate, $\mathrm{CtP}$ ) eliminates the filmmaking phase and therefore enables control of the printing plate's exposure made by computer. CtP technology eliminates the filmmaking phase, but it also results with the reduction of needed material quantities and required time for the production (Limburg, 1994; Seydel, 1996).

In this paper the basis of the graphic reproduction by using the silver halide digital printing plates was described. The changes of the $\mathrm{AgX}$ copying layer and the surface of the aluminium base in the printing process have been observed. The surface characteristics were determined by measuring the relevant surface roughness parameters. In addition, measurements of coverage values on the prints, detailed at smaller print run, were conducted.

Results showed that surface changes on the printing plate are changing during printing process and that these changes influence transfer of the printing ink on the printing substrate. These measurements proved to be of great interest in the graphic reproduction as they enable us to determine consistency of the printing plates during the printing process, to predict the endurance as well as to define the print run which will result with optimal quality prints.
\end{abstract}

Keywords: surface roughness, UV coating, gloss

\section{Introduction}

Conventional reproduction system (analogue reproduction) is characterized by the usage of film, camera, copy technology, and photomechanical (hardened or softened by light) emulsions, as well as mechanical and chemical processes in the printing plate making process. Materials and equipment used for analogue reproduction have reached a stage of development that allows them to sat-

First received: 01.08.2010.

Accepted: 30.09 .2010 isfy very high quality demands in printing plate production and process safety. During plate making process, the master copy (film) is optically transferred onto the photo sensitive layer of the printing plate. A printing plate is produced for each primary colour (cyan, C; magenta, M; yellow, Y; black, K) of the intended print on the basis of the corresponding colour separation (Southworth, 1979; Ihme, 1982). Exposure of the unexposed printing plate in accordance with the image is followed by developing process using the chemical/physical processes appropriate to used material. This is followed by the fi- 
nal treatment of the plate, in which the latter undergoes after-treatment and is prepared for fitting in the press (Walenski, 1975). The printing process consists of following processes: application of damping solution, application of the printing ink and production of reproduction (Fig. 1). The printing plate which consists of texts and illustrations is first covered by the damping solution by means of the damping roller system. The damping solution is absorbed on the nonprinting areas preventing the later possible adsorption of the printing ink onto the same areas. By turning the plate cylinder, the printing plate comes on the inking system and transfers the ink on the printing elements on which the damping solution did not adhere. Printing ink and the damping solution are transferred from the printing plate (plate cylinder) on the offset cylinder which is covered by the rubber blanket which is placed between the plate and impression cylinder, and the printing substrate (most often paper) passes between the offset and impression cylinder (Fig. 1).

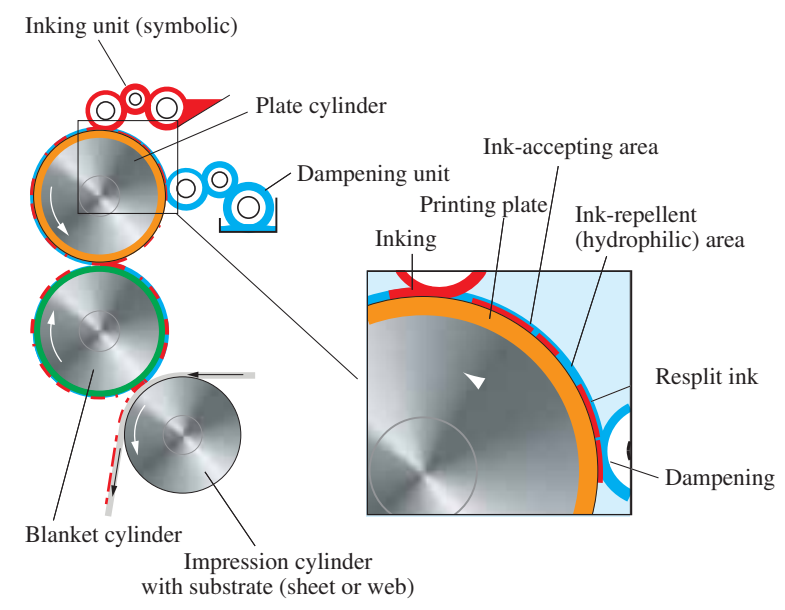

Figure 1. Offset printing (Kipphan, 2001)

The offset cylinder has the role of the ink transfer between the printing plate and the printing substrate making this printing technique indirect. Because of that the printing plate is laterally reversed. Great advantage of such printing technique is the adaptation of the rubber blanket to different substrates. In this way the determined printing quality level even on a bad paper can be maintained. The role of the impression cylinder is to realize the corresponding pressure and to transport the printing substrate. As mentioned through description of the printing process, the printing and nonprinting areas (on the printing plate) must differ in their physicalchemical characteristics. Water adheres to the nonprinting areas and ink to the printing areas. The technique is based on selective damping of the nonprinting areas by the fountain solution. The printing elements and the nonprinting areas are on the same level, i.e. they have negligible geometrical difference of several micrometers. The nonprinting areas are hydrophilic, they attract water, i.e. they are oleophobic because they reject ink while the printing areas are oleophilic, i.e. hydrophobic because they absorb the ink, based on oil. Hydrophobic ability of nonprinting areas is enough making application of the fountain solution first so that it can cover the nonprinting areas and prevent the toning. Consequently, in production of the printing plate it is essential to define necessary physical-chemical characteristics of the printing and nonprinting areas, but also to keep that defined characteristics during printing process.

\section{Printing Plate Production}

Aluminium is most commonly used material in the plate making production. It is used as a foil $0,3 \mathrm{~mm}$ thick and coated with a thin photo-sensitive layer. During the plate production the surface of the aluminium is roughened. The necessary graining of the aluminium surface is made mechanically and/or electrochemically, that is, mechanical/electrochemical graining with subsequent anodic oxidation. This roughness of the aluminium surface is necessary for a number of reasons. The most important one is that it enlarges the contact area which causes better wetting of fountain solution (Pavlovic et. al., 2010). Nevertheless, the surface should not be to rough because it might result with the reduction of sharpness of the screening element on the paper surface, which in turn might cause the decrease of the reproduction quality. Through the printing plate exposure, the silver halide coating is photo chemically decomposed and by developing process exposed light-sensitive areas are removed from the base (aluminium). The thin film of aluminium oxide has a particularly stable water-attracting (hydrophilic) surface with special retention properties (Novakovic et. al., 2009,). Other parts of the surface, with the silver components will, due to its hydrophobic quality accept the printing ink (Fig. 2).

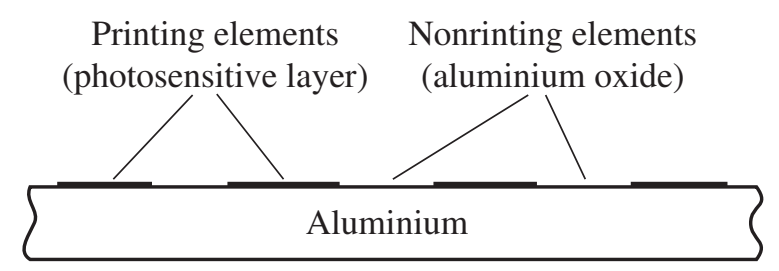

Figure 2. Characteristics of the offset printing plate

During the printing process by friction between the printing plate and the ink rollers, fountain solution rollers and offset cylinder the surface of the printing plates is often worn. The wearing of printing plate is also influenced by chemical substances in printing ink.

This is the reason why a decrease of the ink transfer occurs, which in turn reduces the percentage of the coverage on the paper. The changes of the printing plate surface occur after a certain number of prints and therefore influence their quality (Mahovic et. al., 2003). The standardization of the printing process becomes simpler by predicting the possible changes of the prints and by 
following the parameters which could have influence on their quality. These steps bring certain advantages to the printing houses in the sense of reduction of the reproduction time, as well as the planning of the financial dimension.

\section{Experimental Details}

The wearing of the printing plate surface can indirectly be investigated by measuring the percentage of the coverage of the printing elements on the printing plate and on the prints (Bosner et. al., 1989), and directly, by measuring the changes of the roughness parameters on the printing and nonprinting areas on the printing plate. In this paper the basis parameters for reproduction quality and the consistency of the silver layer during printing process were investigated. Consistency of the silver layer was measured through defining the roughness parameters of the printing plate surface. Roughness parameters have significant role in the printing process because they define the consistency of the copying layer and, upon this, the consistency of the printing plates. The characteristics of the printing plate surface (roughness parameters for silver and aluminium-oxide areas) before the print run and possible changes of the roughness after the print run were investigated.

On the other hand, possible changes of the printing elements coverage causes change of the coverage values on prints. As our market size is relatively small, influence of the print run on the prints was investigated in lower print run values.

Investigation of the roughness characteristics of the printing plate surface was performed by electronical-mechanical equipment with the stylus Perthometer. For measuring the mechanical characteristics of the coverage values on prints the device with the CCD camera, GretagMacbeth iCPlate II Platereader, has been used. Measured parameters have significant importance in the graphic inking reproduction process. Results of this paper have shown in which amount the wearing of the printing plate surface and silver areas influence on print quality.

\section{Measurement}

The surface roughness is a very complex and its estimation demands necessary simplification. It is revealed through the quantification system of surface roughness condition by one-dimensional parameters based on shot of two-dimensional profile on the part of the investigated surface. In regard to the amplitude and the horizontal characteristics of the profile, there are horizontal surface parameters, vertical ones and hybrid ones. The modern equipment for measuring the surface roughness enables measurements of great numbers of parameters, each describing a single characteristic of the surface roughness (Mahovic and Marosevic, 1997). The choice of the roughness parameters which will give the optimal characteristics of the surface depends firstly on the process of its elaboration and the function of investigated surface.

The investigated roughness parameters are defined according to the ISO/DIS 13565-2 (1994) standard on the curve of relative length carrying capacity, so called Abbott's curve (Drevs and Weniger, 1989). Abbott's curve gives the relative share of the material as a function of the line high cross section and describes relative growth of the material share with the increasing profile.

In this paper, the printing plate surface was evaluated through following amplitude parameters:

$R z$ - mean peak-valley height in 10 dots. It describes the differences between middle height of the five highest peaks and the five lowest valleys inside the reference length.

$R a$ - arithmetical mean of the roughness, (roughness average)

$R p$ - the highest peak inside the reference length; and through following hybrid parameters:

$R k$ - core roughness depth, working surface which will influence the consistency of the material (printing plate)

$R p k$ - reduced peak height, main part of the surface which will be worn out through the processing (printing process)

$R v k$ - reduced valley depth.

The surface characteristics were also measured indirectly, by measuring the surface coverage of the printing elements on the prints. The measurements were made by device containing the CCD camera, GretagMacbeth iCPlate II Platereader, for defining the mechanical characteristics of the coverage.

As said before, our market size is relatively small and therefore investigated was print run of 80000 prints. First investigated sample (Sample A) was taken from the beginning of print run, then the $5000^{\text {th }}$, the $10000^{\text {th }}$, the $21000^{\text {th }}$ (Sample B), the $40000^{\text {th }}$ (Sample C), the $60000^{\text {th }}$ and the $80000^{\text {th }}$ (Sample D) print. On all prints, measurement of the coverage value was made for all main colours (cyan, magenta, yellow and black).

\section{Results and Discussion}

The investigation was made on printing plates with $\mathrm{AgX}$ coating before print run (in the results marked with "0"), after 1000 prints (marked with "1000") and after 350000 prints (marked with "350000"). The surface roughness was measured on the silver coating (printing areas, marked with "PA") and on the aluminium-oxide surface (nonprinting areas, marked with "NA"). All the measurements were performed in the same measurements conditions using Gaus filter of limited wave length $\lambda_{\mathrm{B}}=0,8$ $\mathrm{mm}$ with the evaluation length $\mathrm{ln}=0,4 \mathrm{~mm}$ and standard 
stylus RHT 6-50. For more accurate results each printing plate sample has been measured on five places in parallel printing direction. In the Figs. 3 and 4 the middle values of the performed measurements are shown.

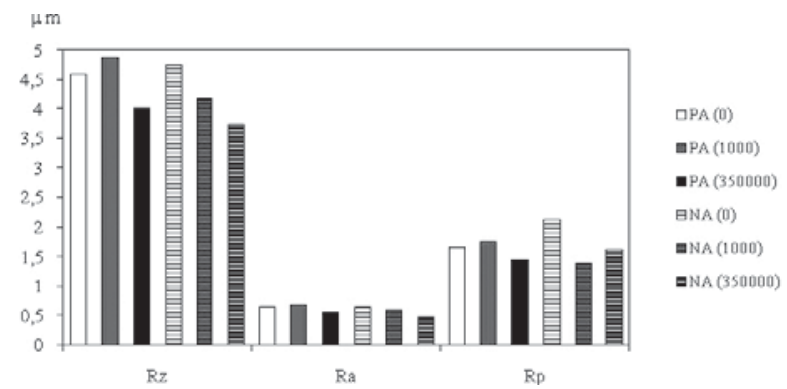

Figure 3. Results of measurements of $R z, R a, R p$ surface roughness parameters

The results of the measurement show that there is a certain reduction of all measured parameters after the print run of 350000 prints. By measuring the amplitude parameters $R z, R a, R p$ it can be seen that there is an increase of 0.1 to $0.3 \mu \mathrm{m}$ on the Ag surface (ink carrier) after 1000 prints. This is most likely the consequence of the residual paper particles (which are transferred from offset cylinder on the printing plate) and ink particles on the ink carrier surface. During the printing process these small particles are placed in the profile valley depth. After the print run of 350000 prints the roughness of the surface decreases. The roughness parameters are also smaller due to mechanical wearing of the printing plate surface. That is to say, during the printing process, in the touching zone between the offset cylinder and the plate cylinder the rubber web slightly slides on the offset cylinder, and therefore causes abrasive damaging of both nonprinting (aluminium-oxide) and printing (Ag) surfaces. The reduction of the surface roughness will directly cause the reduction of the ink transfer from the printing plate onto paper. This will in turn result with prints of poorer quality. By observing these elements on the used printing plates one can notice the disappearance of the smallest printing elements which are important for the appearance of the light tones on the prints.

Measurements of the hybrid roughness parameters $R k$, $R p k, R v k$ have shown that there is a reduction both on

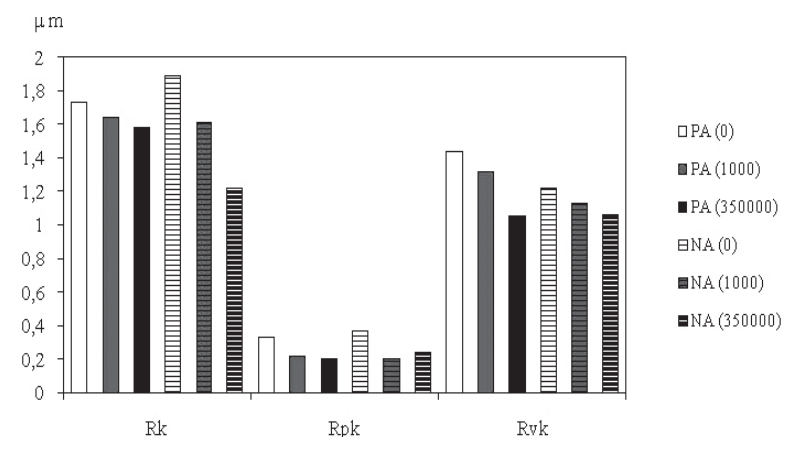

Figure 4. Results of measurements of $R k, R p k, R v k$ surface roughness parameters the Ag surface and on the aluminium-oxide surface. The results are shown in Fig. 4. The reduction of the $R k$ parameter points at the reduction of the roughness core depth. The reduction of the $R p k$ parameter signifies the smoothing of the surface, and the decrease of the $R v k$ parameter points at the reduction of the deeper tracks. Figures 5. to 8. show coverage values on prints of four main colours, black, yellow, magenta and cyan at lower coverage areas.

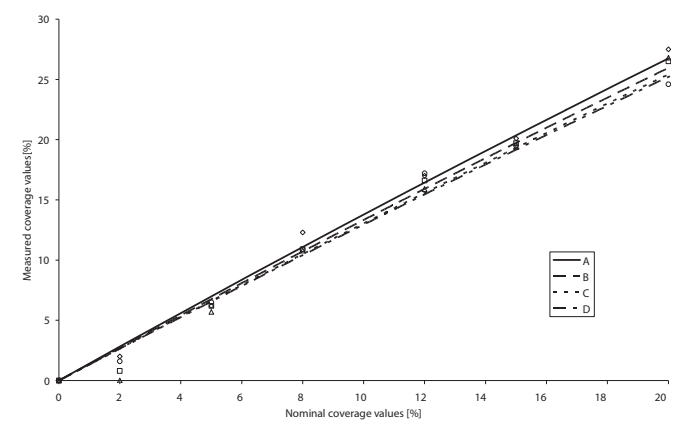

Figure 5. Coverage values of black, $A$ - first print, $B-21000^{\text {th }}$ print, $C-40000^{\text {th }}$ print, $D-80000^{\text {th }}$ print

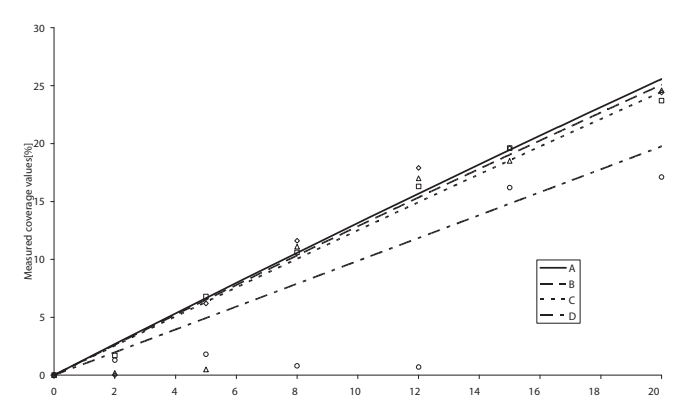

Figure 6. Coverage values of yellow, $A$ - first print, $B-21000^{\text {th }}$ print, $C-40000^{\text {th }}$ print, $D-80000^{\text {th }}$ print

It can be seen that coverage values are reducing its value with increasing of nominal value by all colours. The influence of printing run length on coverage values is smallest with black colour (Fig.5.). Reduce of coverage values is most significant with yellow at the end of printing run (Sample D, Fig.6.). Coverage values of cyan do not show any change between Sample C and Sample D (Fig.8.).

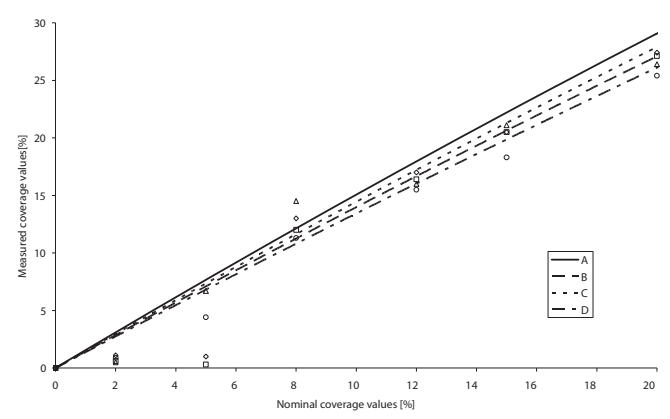

Figure 7. Coverage values of magenta, $A-$ first print, $B-21000^{\text {th }}$ print, $C-40000^{\text {th }}$ print, $D-80000^{\text {th }}$ print 


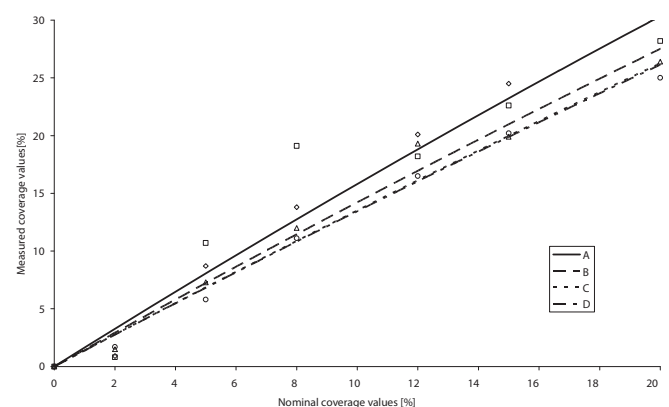

Figure 8. Coverage values of cyan, $A$ - first print, $B-21000^{\text {th }}$ print, $C-40000^{\text {th }}$ print, $D-80000^{\text {th }}$ print

In the middle coverage areas ( $20-80 \%$ coverage value) all colours show similar behaviour as well as in lower coverage areas. Black still has smallest reduce of coverage values (Fig. 9.). With black, magenta and cyan reduce of coverage areas increases with increase of nominal coverage value (Figs. 9., 11., 12.). Yellow Sample D has largest reduce of coverage values (Fig. 10).

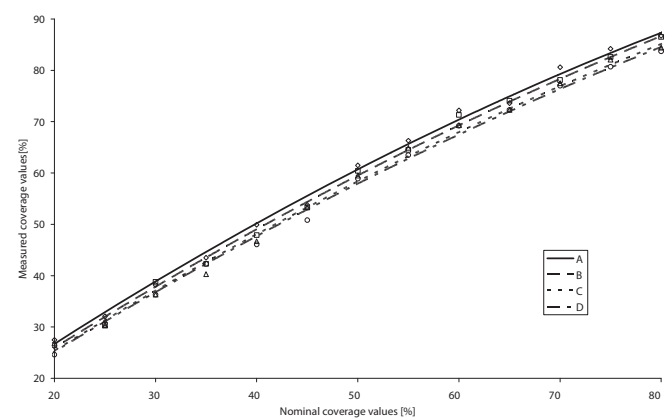

Figure 9. Coverage values of black, $A$ - first print, $B-21000^{\text {th }}$ print, $C-40000^{\text {th }}$ print, $D-80000^{\text {th }}$ print

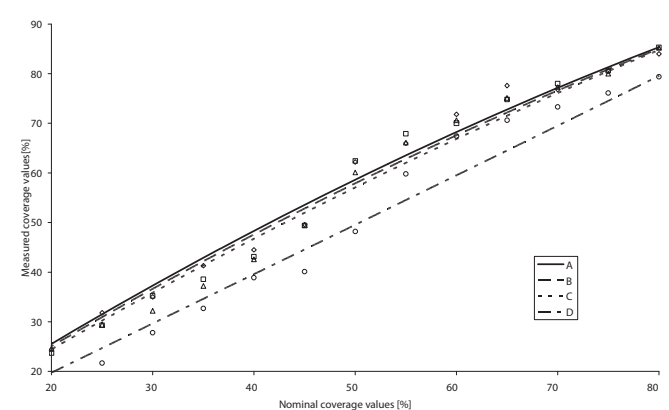

Figure 10. Coverage values of yellow, A-first print, $B-21000^{\text {th }}$ print, $C-40000^{\text {th }}$ print, $D-80000^{\text {th }}$ print

One can see in Figures 14. and 16. that differences between coverage values on Samples A, B, C and D of yellow and cyan are getting smaller with increase of nominal coverage value. The largest difference between first and last $\left(80000^{\text {th }}\right)$ print is in very high coverage areas with black (Fig. 13.). With cyan and magenta curves of Samples B, C and D are nearly the same after $90 \%$ nominal value.

It is assumed that the reduction of the ink transfer on the paper come as a result of wearing of the copying layer on the printing surfaces, that is as a result of the

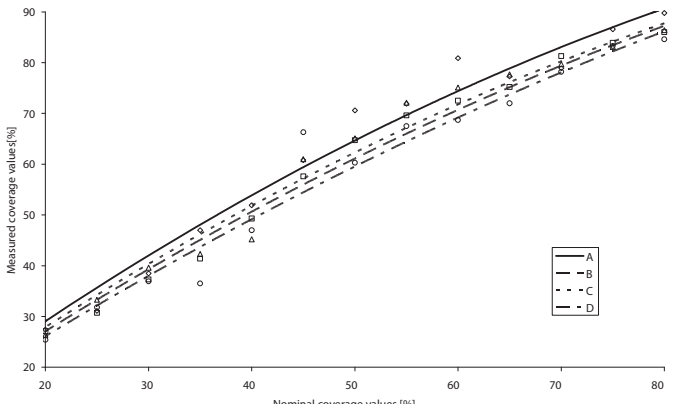

Figure 11. Coverage values of magenta, $A$ - first print, $B-21000^{\text {th }}$ print, $C-40000^{\text {th }}$ print, $D-80000^{\text {th }}$ print

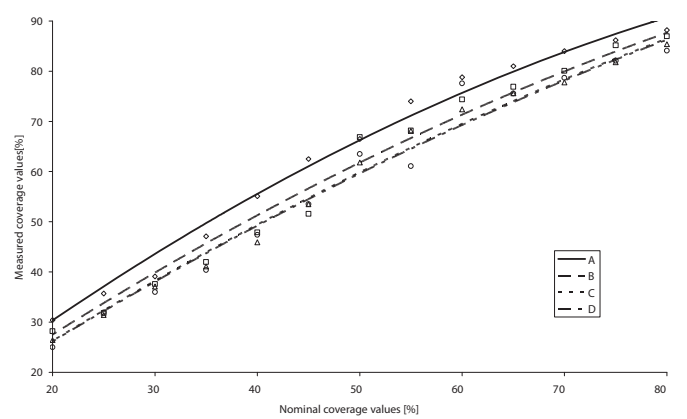

Figure 12. Coverage values of cyan, $A$-first print, $B-21000^{\text {th }}$ print, $C-40000^{\text {th }}$ print, $D-80000^{\text {th }}$ print

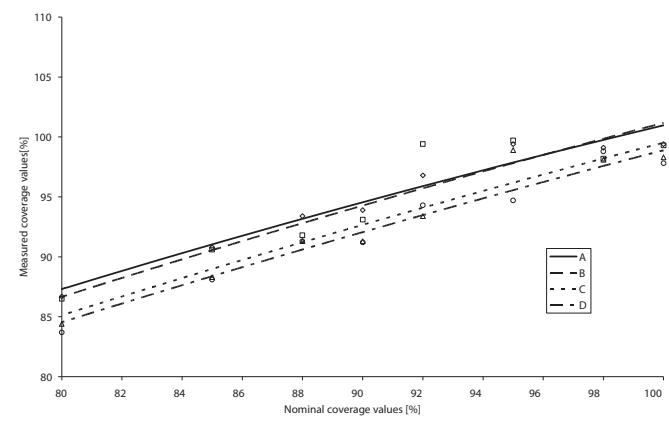

Figure 13. Coverage values of black, $A$ - first print, $B-21000^{\text {th }}$ print, $C-40000^{\text {th }}$ print, $D-80000^{\text {th }}$ print

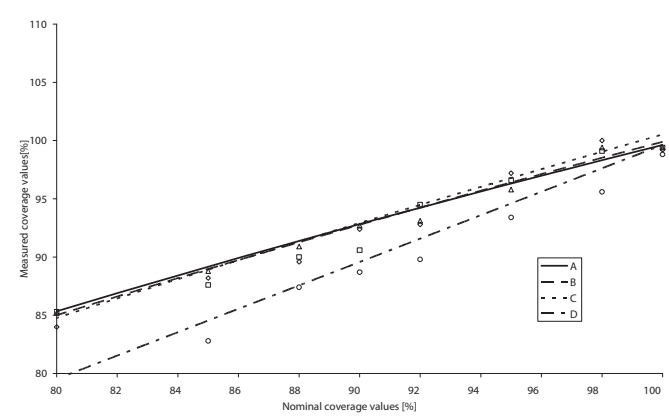

Figure 14. Coverage values of yellow, $A$ - first print, $B-21000^{\text {th }}$ print, $C-40000^{\text {th }}$ print, $D-80000^{\text {th }}$ print

reduction of the printing plates surface roughness. On parts of the printing surfaces which contain copying layer (PA) an aluminium surface arises after the long print run. Such surface will not accept ink and transfer it to the paper due to its characteristics which are different 


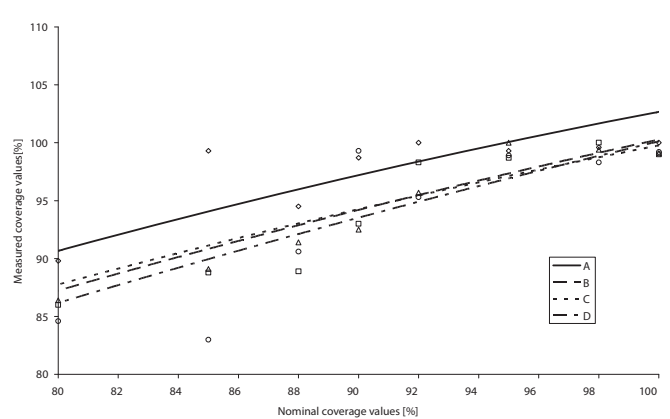

Figure 15. Coverage values of magenta, A-first print, $B-21000^{\text {th }}$ print, $C-40000^{\text {th }}$ print, $D-80000^{\text {th }}$ print

than those of the copying layer. Because of that there is a reduction of ink transfer and the reduction of the surface coverage of the prints.

\section{Conclusion}

This investigation was made to determine influence of the print run on wearing of the silver-halide printing plates. To determine changes on the printing plate, measurement of roughness parameters were conducted. In addition, measurements of the coverage values on prints were made to determine changes in the reproduction of four main colours.

By observing the amplitude and the hybrid roughness parameters it can be seen that the roughness of the surface on the printing plates decreases during the printing process. The defining of the mentioned roughness parameters are important both to the printing plate's manufacturers and to their final users (print houses). The observing of only one of the stated parameters (for example $R a$ - arithmetical mean of the roughness or $R p k$ - reduced peak height, main part of the surface which will be worn out through the printing process) is not the adequate approach to defining the printing plates consistency because the evaluated changes after the print run of the 350000 prints are relatively small.

The results of the coverage value measurements have shown that different printing inks have different role in wearing of printing plates. All results of the coverage values on prints imply that printing process causes decrease of coverage value. This result can indicate that printing inks have specific hard chemical substances that in combination with friction between ink rollers and printing plate damage photoactive layer. Largest decrease in coverage value was detected in printing with yellow. The printing run length has the smallest influence on reproduction of black colour. All colours have the largest decrease of coverage value in middle coverage area.

In conclusion, this investigation has proved that wearing of the printing plate by printing process occurs and as measurement of prints indicated, is influenced, not only by friction between printing plate and offset cylinder and fountain solution and ink rollers, then also by chemical effect of the printing ink substances.

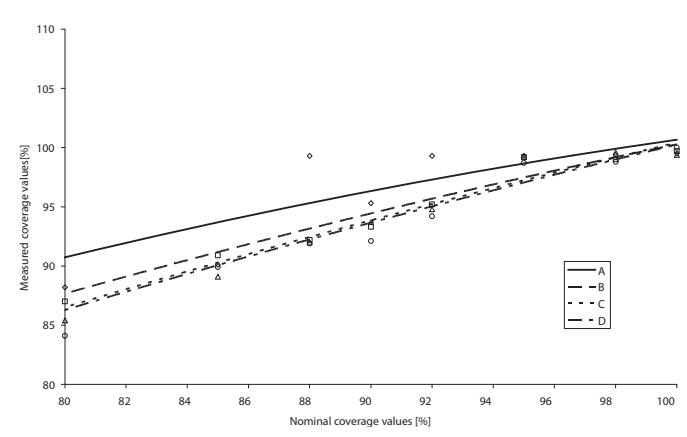

Figure 16. Coverage values of cyan, A-first print, $B-21000^{\text {th }}$ print, $C-40000^{\text {th }}$ print, $D-80000^{\text {th }}$ print

\section{References}

1. Bosner Z., Ferencek B., Korelic O., Trošenje ofsetne tiskovne forme u toku tiska, Acta Graphica 1-1, 43 (1989).

2. Drevs P., Weniger R., Redisovering the Abbott-Firestone Curve-Quality, 15-3, 1989, 50-53.

3. Ihme R., Lerhbuch der Reproduktionstechnik, VEB Fachbuchverlag, Leipzig, 1982, 30-39.

4. Kipphan H., Handbook of Print Media, Springer, Berlin, 2001, 503-626.

5. Limburg M., Der Digitale Gutenberg - Alles was Sie über "Computer to Plate" wissen sollten, GSSGrafik System Service, Aachen, 1994.

6. MacPhee J., Fundamentals of Lithographic Printing, Volume I, Mechanics of Printing, GATFPress, Pittsburg, 1998

7. Mahovic S., Agic D., Gojo M., Mechanical and Optical Differences in Long Run Printing in Conventional and CtP Offset Systems, Proceedings of the 30th International Iarigai Research Conference, Croatia, 219. (2003).

8. Mahovic S., Marosevic G., Surface Roughness of the Offset Rubber Blanket, Acta Graphica 9-1, 1 (1997).

9. Novaković D.,Karlović I., Gojo M.: Influence of the surface characterstics on quality of the offset printing plate, Matrib 2009 International Conference, Croatian society for materials and tribology institute of materials and machine mechanics (slovak academy of sciences), Dublin institute of technology, Faculty of mechanical engineering and naval architecture zagreb, Vela Luka, Croatia, 24-26. June, pp. 142-148, ISBN 978-953-7040-16-1

10. Pavlović, Ž., Novaković, D., Gojo, M, Površinska hrapavost slobodnih površina ofset termalne CTP tiskovne forme, Digitalni sustavi u tiskarstvu, Tiskarsvo 2010, Scientific meeting printers and graphic artist of printing technology, Croatian Academy of Engineering, Stubičke toplice, Croatia, 2010. ISBN 978-953-7064-14-3

11. Seydel M., Computer to Plate: Digital Workflow and Integration into Quality Offset Printing, TAGA Proceedings, Rochester (NY), 634. (1996).

12. Southworth M. F., Color Separation Techniques, Graphic Arts Publishing-2nd Edition, Livonia, N.Y., 1979, 194-226.

13. Walenski W., Einführung in der Offsetdruck, Hanns Eggen GmbH\&Co KG, Hannover, 1975, 215-216. 